\title{
The Power of Openness to Experience, Extraversion, L2 Self-confidence, Classroom Environment in Predicting L2 Willingness to Communicate
}

\section{Irum Fatima}

Graduate Research Student, School of Educational Studies, Universiti Sains Malaysia, fatimairum01@gmail.com

\section{Shaik Abdul Malik Mohamed Ismail}

Assoc. Prof. Dr., School of Educational Studies, Universiti Sains Malaysia, samohame@gmail.com

\section{Zahid Hussain Pathan}

Graduate Research Student, School of Educational Studies, Universiti Sains Malaysia, pathanzahid82@yahoo.com

\section{Ubedullah Memon}

Graduate Research Student, School of Management, Universiti Sains Malaysia, ubedullahsom@gmail.com

In learning English as a foreign language (EFL), classroom is a primary source where learners find opportunities to make communication in the English language and enhance their L2 WTC and L2 communicative abilities. Keeping in view the pivotal importance of classroom environment in shaping EFL learners' WTC, the present research unravels the impact of personality factors (e.g., openness to experience, and extraversion), affective factors (e.g., perceived communicative confidence (PCC), and L2 speaking anxiety), and English classroom environment on L2 WTC. The adopted questionnaire was administered to 234 randomly selected public university students. A three-level hierarchical regression modeling was performed in SPSS (version, 24). The findings showed that affective factors in the study accounted for $33 \%$ of the variance in leaners' L2 WTC. Both personality factors and English classroom environment caused significant changes in L2 WTC model e.g., $(\triangle \mathrm{R} 2=.16)$ and $(\triangle \mathrm{R} 2=.09)$ respectively. The findings also revealed the interrelationship of the six variables and presented the account of L2 WTC in a different EFL social context. The findings have some implications for teaching and learning in an EFL context.

Keywords: L2 WTC, EFL, extraversion, L2 self-confidence, classroom environment

Citation: Fatima, I., Ismail, S. A. M. M., Pathan, Z. H., \& Memon, U. (2020). The Power of Openness to Experience, Extraversion, L2 Self-confidence, Classroom Environment in Predicting L2 Willingness
to Communicate. International
https://doi.org/10.29333/iji.2020.13360a
Journal
of Instruction,
13(3),
909-924. 


\section{INTRODUCTION}

The current cohort of second language acquisition (SLA) research shows the overarching importance of learners' communicative competence in the target language learning. As MacIntyre and Charos (1996) also note, "recent trends toward a conversational approach to second language pedagogy reflect the belief that one must use the language to develop proficiency, that is, one must talk to learn" (p. 3). In a similar vein, Dörnyei (2005) maintains that communicative competence is essential to attain success in the language learning process. Language learners can gain proficiency if they seek out opportunities to use language communicatively (Khajavy et al., 2016). Apropos of learners' communication frequency, MacIntyre, Clément, Dörnyei, and Noels (1998) devised a heuristic model of communication to define learners' WTC in the L2 context. This model has garnered popularity in SLA researches across the world and has been tested in relation to psychological, affective, and situational constructs (Cao, 2014; Fushino, 2010; Khajavy et al., 2016; Lin, 2018; Peng \& Woodrow, 2010; Rafiee \& Abbasian-Naghneh, 2018; Yashima, MacIntyre \& Ikeda, 2018). The dominant theme gleaned from these studies explains that L2 WTC has a central role in L2 development and learning outcome.

In EFL/ESL context, WTC is deemed as an individual differences (IDs) variable and refers to language learners' predispositions in L2 communication. L2 WTC indicates learner's "readiness to enter into discourse at a particular time with a specific person or persons, using an L2" (MacIntyre et al., 1998, p. 547). This definition includes both trait-like (e.g. individual factors, such as personality) and state-like (e.g. transient communicate behaviour that fluctuates over time and situation) learner's inclination to communicate in L2 (Peng \&Woodrow, 2010).

The previous researches have studied L2 WTC using the scale developed by McCroskey (1992) in which student participants are asked to report their L2 WTC inside and outside classroom situations (Ghonsooly, Khajavy \& Asadpour, 2012; Öz, Demirezen \& Pourfeiz, 2015; Yashima, Zenuk-Nishide \& Shimizu, 2004). The findings of these studies seem to target learners L2 WTC in an ESL context. Contrarily, in an EFL context, as in the case of Pakistan, it is the EFL classroom where learners have access to the target language (Oxford \& Shearin, 1994). In fact, language classroom is the primary source where EFL learners have chances to interact in the English language. Therefore, probing EFL learners' WTC by placing them in a situation which they rarely experience outside the classroom may not portray a true picture of their L2 WTC (Khajavy et al., 2016). Hence, there is an indispensable importance of EFL classroom specifically in the Pakistani context where learners communicate in English with their English teachers and peers. To-date there is a scarcity of researches on underlying factors of L2 WTC in classroom context particularly in Pakistan (Cao, 2011; Khajavy et al., 2016, Peng, 2012). The present study investigates psychological, affective, and contextual constructs that are likely to affect Pakistani learners' WTC in an EFL classroom context. The results of the present study are insightful to understand L2 WTC in general and in Pakistan in particular. The present study also adds to knowledge of English instructors about the factors that exert influences on learners' L2 WTC. 


\section{LITERATURE REVIEW}

\section{WTC}

WTC is regarded as an ID construct which explains individuals' attributes associated to their first language (L1) and second language (L2) communication. Initially, WTC was introduced to ascertain the trait-like personality that people exhibit in L1 communication (McCroskey \& Baer, 1985). This concept was later associated to L2 communication context (MacIntyre and Charos, 1996) and was linked with psychological, linguistics, and situational variables as delineated in the heuristic pyramid-shaped model propounded by MacIntyre et al. (1998). According to this model, the top three layers exhibit transitory, dynamic and situation-specific aspects of learners' L2 communication. On the contrary, the bottom three layers outline more stable or trait-like variables affecting learners' L2 WTC. In other words, the model portrays both permanent and transitory variables that influence language learners' WTC.

The previous researches have largely studied L2 WTC that support MacIntyre et al.'s (1998) model. For example, the trait-like WTC-oriented studies have identified personal individual characteristics affecting L2 WTC, such as personality $(\mathrm{Oz}, 2014$; Rafiee \& Abbasian-Naghneh, 2018), sex (Donovan \& MacIntyre, 2004; MacIntyre, Baker, Clément \& Donovan, 2002), anxiety (Ghonsooly et al., 2012), self-confidence (Ghonsooly et al., 2012; Yashima, 2002), international posture (Ghonsooly et al., 2012), and motivational self-system (Öz et al., 2015). On the contrast, the proponents of situation-specific WTC accentuate variables, such as context interlocutors (Cao \& Philip, 2006; MacIntyre, Burns \& Jessome, 2011) and classroom environment (Joe, Hiver \& Al-Hoorie, 2017; Khajavy et al., 2016; Peng \& Woodrow, 2010). The recent studies have also explored the dynamic nature of L2 WTC by conceptualizing it with both individual and situation-specific non-linear variables (Cao, 2011; Pawlak \& Mystkowska-Wiertelak, 2015; Syed \& Kuzborska, 2018).

The Proficiency level in the target language also implicates language learners' WTC. For example, Tan and Phairot (2018) examined the difference in WTC inside and outside the English classroom across twelfth-grade Thai students with different proficiency levels ( e.g., low, moderate, and high). The findings showed that high proficient learners exhibited greater WTC inside the classroom than the moderate and low proficient groups. Concerning the difference in WTC level outside the classroom, high proficient learners were more willing to communicate in L2 than the low proficient learners. Additionally, the results of this study also indicated the significant positive role of proficiency in predicting language learners' L2 WTC inside and outside the classroom.

Basöz and Erten (2018) investigated Turkish university English language learners' WTC. The results demonstrated that English language learners had a moderate level of WTC. Moreover, the results also signified that the learners were more willing to communicate outside the classroom. Recently, L2 WTC has also been studied in relation to learners' extramural digital (ED) environment. Studying the Koreans students' WTC in the CALL environment, Lee (2019) found that "familiarity with interlocutors and 
communities, and L2 self-confidence" were the key sources that influenced university students' WTC. This study opened a new vista of knowledge for the English language teachers to help English language learners enhance their WTC while implementing extramural digital activities in their teachings.

Following ecosystems theory, Peng (2012) studied Chinese university students WTC. This study recruited four students who were interviewed six times over a period of one and a half-semester. Besides semi-structured interviews, classroom observations, and learning journals maintained by the study participants were used as data collection tools. The results showed that there were six factors that influenced language learners' WTC: "learner beliefs, motivation, cognitive factors, linguistic factors, affective factors, and classroom environment".

Prior researches come to an agreement that WTC is a multi-faceted construct that emerges due to the influence of numerous psychological, linguistics, and situational underlying factors. Of all the variables affecting L2W TC, L2 self-confidence is regarded as the leading factor and defined as "the overall belief in being able to communicate in the L2 in an adaptive and efficient manner" (MacIntyre et al., 1998, p. 551). Some researches treat communicative competence and L 2 speaking anxiety as two distinct constructs (MacIntyre et al., 2002; Öz et al. 2015) whereas, for some researchers, it is a composite variable that affects L2 WTC. L2 self-confidence has emanated as the potential predictor of L2 WTC (Khajavy et al., 2016, Lin, 2018; Yashima et al., 2004).

\section{Personality}

In the L2 WTC model (MacIntyre et al. 1998), personality is regarded as a distal antecedent of L2 WTC. Personality is commonly associated with big-five orthogonal dimensions/factors which explain individuals' cognitive, behavioural, and emotional characteristics (Costa \& McCrae, 1992). Different personality traits are linked to different learning aspects, such as academic achievement, self-regulated learning strategies, PCC, and speaking confidence (Bidjerano \& Dai, 2007; Ntalianis, 2010; Furnham \& Monsen, 2009). In the context of L2 WTC, openness to experience, agreeableness, and extraversion are closely associated to language learners' L2 WTC (MacIntyre \& Charos, 1996; Oz, 2014). Similarly, openness to experience also emerged as the prognostic of English language learners' WTC in Poland (Piechurska-Kuciel, 2018). In the Iranian context, extraversion and openness to experience facilitated EFL learners' WTC (Khany \& Nejad, 2017). These facts suggest that of the five-personality dimension, openness to experience, and extraversion are related to L2 WTC and should be further explored in different learning contexts. As WTC is one of the IDs, personality as an ID variable is likely to cultivate and foster L2 WTC.

Piechurska-Kuciel (2018) investigated the impact of openness to experience on secondary grammar school students' WTC in Poland. The findings of the step-wise regression revealed that open personality trait exerted a direct influence on learners' WTC and showed an indirect effect on learners' WTC through the mediation of communicative competence and language learning anxiety. This study confirmed the 
potential role of openness to experience as a personality dimension that influenced language learners' voluntary predisposition to initiate communication in the target language.

In addition, Khany and Nejad (2017) also conceptualized two dimensions of personality (e.g., openness to experience, and extraversion) with Iranian EFL learners' L2 WTC and unwillingness to communicate (L2UWTC). The findings of the SEM model showed that both openness and extraversion personality traits were closely interlinked and predicted learners' L2 WTC. On the contrary, both the personality dimensions insignificantly predicted their L2UWTC. These findings suggest that open and extravert language learners are curious, and leave no stone unturned to gain new experiences. The findings of this study also postulated that less open and less extraverted learners were unwilling to initiate communication in the target language.

As personality has both facilitating and debilitating role in a second language learning (Wen \& Clément, 2003), openness to experience and extraversion facilitates learners' predisposition towards L2 communication (Khany \& Nejad, 2017; Piechurska-Kuciel, 2018; Oz, 2014). Such a knowledge compliments the arguments that openness to experience is closely related to L2 learning and L2 WTC (Dörnyei, 2005), and extraversion fosters target language use (Furnham,1990). However, due to the inconsistent findings on the direct and indirect relationship of personality aspects with L2 WTC, studies need to be carried out in different social contexts so that existing knowledge on the matter can be thoroughly understood.

\section{Self-confidence}

According to MacIntyre et al. (1998), self-confident L2 learners carry a belief that they are capable of making communication in the target language effectively. In other words, self-confident language learners trust their abilities and skills to be able to use the L2 language in a meaningful communication. They do not exhibit a sense of fear (e.g. language anxiety) that may hinder them to accomplish their L2 learning goals. Selfconfidence is a composite variable that encompasses a high PCC and a low language anxiety (Clément, 1980, Peng \& Woodrow, 2010). PCC indicates learners' own assessment of their skills in the target language (Khajavy et al., 2016; Peng \& Woodrow, 2010). On the contrary, language anxiety is associated to learners retarded feelings, worries, and faded away emotions to use or learn the target language (MacIntyre, 1999). Both PCC and low language anxiety are considered as the most immediate antecedents of L2 WTC (MacIntyre, 2007). Learners' self-perceived L2 competence is related to their actual L2 competence. Therefore, to determine language learners' communicative competence, previous studies (Khajavy et al., 2016; Peng \& Woodrow, 2010) have garnered learners' own perceptions of their L2 competency instead of relying on their final grades. According to Canale and Swain (1980), there are four constituents of communicative competence (e.g., grammatical, strategic, discourse, and sociolinguistic competencies). Language anxiety is a psychological construct that impacts L2 learning process and has its role in shaping learners' L2 selfconfidence. In other words, high language anxiety impedes L2 learning outcomes and vice versa. For example, low anxiety leads to more self-confidence, which in turn 
generates positive results in L2 learning. Additionally, less language anxiety also produces the stronger motivation that is essential to the target language learning (Yashima, 2002).

Previous studies have drawn a conclusion that L2 PCC is one of the indispensable internal variables that enhances learners' L2 WTC. Studying L2 WTC of Iranian undergraduates, Khajavy et al. (2016) found that PCC was the one of the potential variables that directly impacted Iranian students' L2 WTC. In another study on the students of eight universities in China, Peng and Woodrow (2010) found PCC was closely interlinked with L2 WTC. Additionally, Ghonsooly et al. (2012) explored Iranian university students' L2 WTC in relation to its underlying variables. The results revealed that L2 self-confidence showed a positive significant impact on learners' L2 WTC.

Drawing on socio-educational framework and L2 WTC model, Yashima (2002) studied the Japanese EFL students' WTC. The findings generated interesting facts that learners' self-confidence was affected by their level of motivation, which in turn impacted their WTC. These findings suggest that stronger motivation carries a prognostic value for learners' L2 self-confidence. High motivated learners are also less anxious and produce positive outcomes in L2 learning. High confident L2 learners seem to be devoid of fear of committing mistakes and are enthusiastic to particulate in L2 communication in order to learn the target language effectively.

In some studies, self-confidence has emerged to have more positive influence on learners' L2 WTC than motivational factors. For example, the study (Öz et al., 2015) on EFL learners enrolled EFL teacher education program in Turkey revealed that EFL learners' WTC was predicted by their communicative competence and apprehension. On the contrary, motivation indirectly predicted learners' WTC.

To test the L2 model of communication in relation to L2 WTC, Fallah (2014) carried out the study on Iranian university students majoring in English language. The findings revealed that L2 self-confidence could predict EFL learners' WTC. In addition, shyness was the significant negative predictor of learners'L2 self-confidence. These findings suggest that shy English language learners lack L2 confidence and exhibit less volition to communicate in the target language.

\section{Classroom Environment}

Language classroom has a pivotal role to influence learners' L2 WTC. In an EFL context, it is a key source for learners where they use the English language with their teachers and peers (Brown, 2007). This view is also very important for the present research to study Pakistani learners' WTC in a context where they access the English language. Besides some elite class students whose parents also communicate with them in the English language, majority of the Pakistani EFL learners use this language in the English classrooms. Therefore, the classroom context cannot be ignored while studying WTC in an EFL context. Language classroom context has been studied as the situationspecific antecedent of L2 WTC (Khajavy et al., 2016; Peng \& Woodrow, 2010). Research has shown that teachers' behaviour and teaching style, classroom atmosphere, 
class size, and classmates are the essential constituents of the language classroom environment (Dörnyei \& Kormos, 2000; Peng, 2012; Peng, Zhang \& Chen, 2017; Wen \& Clément, 2003).

Prior research (Khajavy et al., 2016; Peng \& Woodrow, 2010) focuses on three components that constitute the language classroom environment, such as teacher support, student cohesiveness, and task orientation. Teachers' verbal and non-verbal behaviour in the classroom fosters the relationship with students and pave the way for effective learning atmosphere (Fallah, 2014). Additionally, teachers' classroom management and teaching style also provoke learners' L2 WTC (Peng, 2012). In the Iranian EFL context, teachers' behaviour, and teaching style exerted potential influence on learners' engagement in classroom learning (Khajavy et al., 2016). Student cohesiveness refers to their mutual understanding and the cooperation they show to each other in learning process (Peng \& Woodrow, 2010). Task-orientation indicates students' realization to accomplish the assigned task (Khajavy et al., 2014; Peng \& Woodrow, 2010). The tasks designed following appropriate situational cues (e.g., content, and the nature of activity) are likely to enhance students' engagement in the tasks (Cao, 2011; Peng, 2012).

In Chinese EFL context, classroom environment influenced learners' L2 WTC with a small effect size (Peng and Woodrow, 2010). The reason for this finding was associated with the Chinese culture, such as teachers' authoritative nature in the classroom and students' unwillingness to evaluate teachers. Another study by Khajavy et al. (2016) depicted a classroom environment as the strongest predictor of Iranian EFL learners' WTC. In fact, these findings draw the crucial importance of the classroom environment to foster L2 WTC. However, the inconsistent findings regarding the low and high effect of classroom environment on L2 WTC warrant further research.

\section{METHOD}

\section{Participants}

A total number of 234 EFL undergraduate students (male, $\mathrm{n}=126,53.8 \%$; female, $\mathrm{n}=$ $108,46.2 \%$ ) were randomly selected from a public University situated in the metropolitan city of Balochistan, Pakistan. The mean age of student participants was 20.51 ranging from 18 to 27 years. All the recruited participants had the exposure of English language for 10 years in their former education. At their current educational institute, English is the medium of instruction besides a few humanity subjects which are taught in indigenous languages (Urdu, Pashto, Brahvi, and Pashto). However, all these students, regardless of their majors, are required to take English as a compulsory subject at their current university. Additionally, they did not have any experience of living or studying abroad. Specifically, the student participants were enrolled in different disciplines such as education, arts and social sciences, languages, and hard and life sciences.

\section{Instruments}

WTC: Ten items $(\alpha=0.84)$ on a 6-point Likert Scale originally designed by Weaver (2005) and used by Khajavy et al. (2016), Peng and Woodrow (2010) were employed to 
measure EFL learners' WTC. Of the ten items, the six items $(\alpha=0.74)$ were based on learners' WTC in meaning-focused activities (e.g., doing a role play in English class), and four items $((\alpha=0.86)$ were based on leaners' WTC in the form-focused activities (e.g., asking group mates about the pronunciation of words).

Openness to experience: Ten items $(\alpha=.81)$ based on a 5-point Likert scale were adopted from the Big-five inventory (John \& Srivastava, 1999). Openness to experience assesses how student participants are ingenious, insightful, curious, foresighted, and artistic.

Extraversion: Eight items $(\alpha=.89)$ based on a 5-point Likert scale were adopted from the Big-five inventory (John \& Srivastava, 1999). This personality trait refers to student participants' energetic, assertive, gregarious, active, and outspoken nature.

Perceived Communicative Competence: Six items $(\alpha=.79)$ originally developed by Weaver (2005) and used by Khajavy et al. (2016), and Peng and Woodrow (2010) were adopted. The items were based on an 11-point can-do scale ranging from $0 \%$ to $100 \%$. All the items meant to assess the percentage of the time student participants were competent to carry out communication in the English language.

Communication anxiety: To measure student participants' speaking anxiety in the classroom, six items $(\alpha=.76)$ based on a 6-point Likert scale (Horwitz, Horwitz \& Cope, 1986; Woodrow, 2006) and used by Peng and Woodrow (2010) were employed in the present study. All the items assessed student participants' L2 speaking anxiety in an EFL classroom setting, such as giving a presentation in front of class fellows, answering to teacher's questions, and taking part in role-play activities.

English Classroom Environment: Thirteen items $(\alpha=.82)$ based on a 6-point Likert scale originally designed by Fraser, Fisher and McRobbie (1996) and used by Khajavy et al. (2016) and Peng and Woodrow (2010) were adopted. This composite construct involved teacher support, student cohesiveness, and task-orientation.

\section{Procedures}

The questionnaire comprising demographic information and six variables (L2 WTC, openness to experience, extraversion, PCC, L2 speaking anxiety, and classroom environment) was administered to 234 university students. Prior to the administration of the questionnaire, formal consent was sought from the head of the departments. Later, all the student participants were informed of the nature of the study and were also assured of the anonymity of their identities. They were also assured that their participation in the current study was solely voluntary and optional and would not affect their English course grades. All the student participants responded to the questionnaire in the presence of their English teacher.

\section{Data Analysis}

The Data of 234 participants were used to perform descriptive and inferential (correlation and a three-level hierarchical regression modeling) analyses. First, the items on each variable were combined and then averaged for the subsequent analysis. Second, 
Pearson's Correlation analysis was performed so as to examine the direction and strength in the relationship among L2 WTC, affective factors (communicative confidence, L2 speaking anxiety), personality (openness to experience, extraversion), and situational variable (English classroom environment).

Finally, to assess the power of PCC, anxiety, openness to experience, extraversion, and classroom environment in predicting EFL learners' WTC, A three-level hierarchical regression analysis was performed. It is a statistical technique to examine the power of each independent variable in predicting a dependent variable in two or more than two blocks (Pallant, 2013). In the first block, the most immediate antecedent of L2 WTC (PCC, and L2 speaking anxiety) were entered. The second block included the distal antecedents of L2 WTC (openness to experience, and extraversion). Finally, the situational antecedent of L2 WTC (English classroom environment) was inserted in the third block. Adjusted R2 value (explains how much independent variables account for variance in the criterion variable), R2 change value (explains how much variance each independent variable accounts for in the criterion variable while controlling the rest of independent variables), and $\beta$ weights (explain the strength of the influence of each dependent variable on the criterion variable) were taken into account to interpret the results (Tabachnick \& Fidell, 2001).

\section{FINDINGS AND DISCUSSIONS}

First, descriptive statistics and correlation of all the variables of the study were calculated. Table1 illustrates that there was a medium, positive association of openness to experience $(r=.469, p<.01)$, extraversion $(\mathrm{r}=.464, \mathrm{p}<.0001), \mathrm{PCC}(r=.480$, $p<.0001)$, and classroom environment had a strong, positive correlation $(r=.542$, $\mathrm{p}<.0001)$ with learners' L2 WTC. Contrarily, L2 speaking anxiety had a medium, negative correlation with learners' L2 WTC $(r=-.405, p<.0001)$.

Table 1

Relationship among Variables

\begin{tabular}{llllllll}
\hline Variables & $\mathrm{M}(\mathrm{SD})$ & 1 & 2 & 3 & 4 & 5 & 6 \\
\hline 1. L2 WTC & $4.94(.75)$ & - & & & & & \\
2. Openness to experience & $3.59(.50)$ & $.469^{* *}$ & - & & & \\
3. Extraversion & $4.22(.71)$ & $.464^{* * *}$ & $.244^{* *}$ & - & & \\
4. Perceived communicative & $4.67(.87)$ & $.480^{* *}$ & $.229^{* *}$ & $.259^{* *}$ & - & & \\
competence & & & & & & & \\
5. L2 speaking anxiety & $1.78(.75)$ & $-.405^{* *}$ & $-.139^{* *}$ & $-.287^{* *}$ & $-.157^{* *}$ & - & \\
6. Classroom environment & $4.89(.63)$ & $.542^{* *}$ & $.200^{* *}$ & $.270^{* *}$ & $.248^{* *}$ & $-.268^{* *}$ & - \\
\hline
\end{tabular}

**. Correlation is significant at the 0.01 level (2-tailed); *. Correlation is significant at the 0.05 level (2-tailed).

Second, prior to running the hierarchical multiple regressions, the basic assumptions of multicollinearity were met. For example, independent variables at least show some relationship with criterion variable (e.g., L2 WTC) preferably above $(\mathrm{r}=.3)$. Additionally, the relationship among the independent variables of the study should not exceed ( $r=.7$ or more) (Tabachnick \& Fidell, 2001). After meeting these assumptions 
(see, Table 1 above), the hierarchical multiple regression model was run as displayed in the following Table 2 .

Table 2

A Three-level Hierarchical Model

\begin{tabular}{lllll}
\hline Block & Variables & Adjusted $\mathrm{R}^{2}$ change & $\beta$ & Std. Error \\
\hline 1 & perceived communicative competence & & $.43^{* *}$ & .04 \\
& L2 speaking anxiety & & $-.34^{* *}$ & .05 \\
2 & Openness to experience & .16 & $.32^{* *}$ & .04 \\
& Extraversion & & $.25^{* *}$ & .03 \\
3 & English classroom environment & .09 & $.33^{* *}$ & .05 \\
\hline
\end{tabular}

Criterion Variable: L2 WTC

$*$ Adjusted $\mathrm{R}^{2}=.33$ for block $1, * * \mathrm{p}<.001$.

The results in the first block showed that PCC $(\beta=.43, p<.001)$, and L2 speaking anxiety $(\beta=-.34, p<.001)$ were the significant predictors of L2 WTC. Both the variables explained $33 \%$ of the variance in leaners' L2 WTC with large effect size (ES) $\left(R^{2}=.33, p<.001, f^{2}=0.42\right)$.

The second block of hierarchical regression that included distal antecedents of WTC e.g., openness to experience $(\beta=.32)$ and extraversion $(\beta=.25)$. They caused a significant increase in the model $\left(\Delta R^{2}=.16, p<.001, f^{2}=.19\right)$ with a medium ES. Both openness to experience and extraversion accounted for $16 \%$ variance in learners' L2 WTC.

In the third and the last block of the model, the situational variable e.g., English classroom environment $(\beta=.33)$ also caused a significant change in the variance of L2 WTC with a small ES $\left(\Delta R^{2}=.09, p<.001, f^{2}=.098\right)$. It can be inferred that the English classroom environment accounted for 9\% of the increase in learners' L2 WTC.

These findings provide some empirical evidence of the psychological, affective, and situational variables shaping Pakistani EFL learners' WTC in the classroom setting. The results of the study corroborate past researches in which L2 communication competence, which is defined by PCC and L2 speaking anxiety, emerged as the most immediate antecedent of learners' L2 WTC (Khajavy et al., 2016; Peng \& Woodrow, 2010; Yashima, 2002). These findings suggest that PCC and less L2 speaking anxiety constitute Pakistani EFL leaners' L2 confidence, and it ultimately leads to their L2 WTC.

The findings concerning block 2 of the model, openness to experience, and extraversion also emerged as significant predictors of L2 WTC. However, the predictable power of both personality traits is lower than PCC and L2 speaking anxiety. These findings echo the previous researches in which openness to experience, and extraversion emanated to have a direct impact on L2 WTC (Khany \& Nejad, 2017; Oz, 2014; Piechurska-Kuciel, 2018). Openness to experience also indirectly influences L2 WTC through the mediation of attitudes (Ghonsoolye et al., 2018; Lin, 2018). Of the two personality traits in the present study, openness to experience is the potential predictor of Pakistani EFL learners' L2 WTC. Language learners with an acute openness strive to learn the target 
language so as to meet their set targets. The key features associated to openness, such as novelty, inquisitiveness, intellectuality, creativeness, and seeking pleasure, are closely related to second language learning and L2 WTC (Dörnyei, 2005). Additionally, open learners not only show lower L2 speaking anxiety and higher WTC, but they also exhibit a curiosity to avail opportunities to communicate in the English language (PiechurskaKuciel, 2018). Similarly, extravert language learners are less anxious (Dewaele, 2002), and are inclined to L2 communication more than introverts (Dewaele \& Furnham, 2000). It is because both openness to experience and extraversion share some overlapping characteristics, such as non-conservativeness, inquisitiveness, and curiosity to seek novelty features of open individuals are closely akin to extravert's features of being talkative, active, sociable, and passionate (Dörnyei, 2005). Hence, the gregarious nature of extraverts leads to their high L2 WTC (Khany \& Nejad, 2017).

These findings provide some empirical evidence of the psychological, affective, and situational variables shaping Pakistani EFL learners' WTC in the classroom setting. The findings of the study corroborate past researches in which L2 communication competence, which is defined by PCC and L2 speaking anxiety, emerged as the most immediate antecedent of learners' L2 WTC (Khajavy et al., 2016; Peng \& Woodrow, 2010; Yashima, 2002). These findings suggest that PCC and less L2 speaking anxiety constitute Pakistani EFL leaners' L2 confidence, and it ultimately leads to their L2 WTC.

Contrarily, learners with low openness are likely to be conventional and abstain from L2 communication and learning. They reckon language learning as ambiguous and put fewer efforts to attain L2 success (Piechurska-Kuciel, 2018). Similarly, students lacking extraversion tend to be reserved, less optimistic and quiet. They prefer to be alone. It does not implicate them to be shy or depressed, but they simply avoid social involvement. Since language learning requires learners to seek out every available learning opportunity, open and extravert learners actively take part in foreign language acquisition-related activities.

Regarding the findings depicted in block 3 of the hierarchical regression model, English classroom environment caused an increase in Pakistani EFL learners' L2 WTC. Although this situational variable was not as powerful as PCC, and L2 speaking anxiety to predict L2 WTC, it $(\beta=.33)$ showed a better predictability power for L2 WTC than distal antecedents of L2 WTC e.g., openness to experience $(\beta=.32)$, and extraversion $(\beta$ $=.25)$. In an EFL context, previous studies have also concluded that the classroom environment facilitates and augments leaners' L2 WTC (Khajavy et al., 2016; Peng \& Woodrow, 2010). In the Pakistani context, English classroom has crucial importance where leaners often get a chance to initiate communication in English with their English subject teachers and classmates. However, the impact of English classroom environment on Pakistani EFL learners' L2 WTC was quite small and it calls for further research. Such a finding may be attributed to the popularity of the grammar-translation method (GTM) (Warsi, 2004) which accentuates on students' reading and writing skills to pass English compulsory subject written examination. Whereas, both listening and speaking skills are not assessed in the final examination. Despite the prevailing conditions, 
students strive to enhance their target language speaking abilities since they know the importance of English language that is the official language of the country and is a key source for the job interviews.

\section{CONCLUSSION AND RECOMMENDATIONS}

The present study tested psychological, affective, and situational variables in relation to Pakistani EFL learners' L2 WTC in the classroom context. The findings suggest that PCC and L2 speaking anxiety were the most significant predictors for L2 WTC. Additionally, personality traits (e.g., openness to experience, and extraversion), and English classroom environment also added to the significance of L2 WTC model. The overall results suggest EFL teachers to know the affective factors and personality traits of EFL learners to facilitate them to enhance their L2 WTC. English Classroom is a key source for EFL learners where teachers can help them achieve high L2 WTC by "providing a good classroom environment, including teacher support, cooperation among the students, and challenging tasks, give students more autonomy in learning English" (Khajavy et al., 2016, p.173). Teachers can create a stimulating and supportive learning environment to foster the cognitive, social, and personal development of learners. Such an environment encourages learners' willingness to participate in learning activities (Yashima et al., 2018).

Incorporating task-oriented learning activities can promote learners' engagement in learning activities. Task-based activities, such as role play, task-completion, and group discussions provide learners a ground to make authentic and meaningful communication in the English language. In such a learning environment, students are not only motivated and goal oriented, but they are also persistent, cooperative, flexible, and self-disciplined to accomplish assigned tasks (Boekaerts \& Cascallar, 2006). Additionally, such activities can also expand learners' motivation and PCC to make authentic communication in the English language.

This study presents the snapshot of personality, affective, and situational underlying factors of 12 WTC in Pakistani context using hierarchical regression modeling. As no study can be exhaustive in itself, therefore the findings of the present research are to be interpreted with some cautions. Although the present study included the sample from the biggest and the oldest public university of the province, their responses may not represent the say of the entire province or country students. Moreover, as the present study studied two personality dimensions of the big-five personality model, the interaction of the rest of three personality dimensions with Pakistani EFL learners' WTC cannot be concluded. To overcome these limitations, future studies are suggested to include a diverse population across the country and investigate the contribution of the rest of the personality factors. Future studies are also advised to use structural equation modeling (SEM) to test the complex relationship among psychological, affective, and situational underlying antecedents of Pakistani EFL learners' WTC. Notwithstanding the limitations, this study benefits Pakistani EFL teachers to know the personality dimensions of their students and adopt teaching methods, techniques, and approaches that may enhance EFL learners' 12 self-confidence and reduce their 12 speaking anxiety to attain higher $12 \mathrm{WTC}$ and 12 learning. 


\section{REFERENCES}

Basöz, T., \& Erten, I. H. (2018). Investigating tertiary level efl learners' willingness to communicate in English. English Language Teaching, 11(3), 78-87.

Bidjerano, T., \& Dai, D. Y (2007). The relationship between the big five model of personality and self-regulated learning strategies. Learning and Individual Differences, 17, 69-81.

Boekaerts, M., \& Cascallar, E. (2006). How far have we moved toward the integration of theory and practice in self-regulation? Educational Psychology Review, 18, 199-210.

Brown, H. (2007). Principles of language learning and teaching. White Plains, NY: Pearson Longman.

Canale, M., \& Swain, M. (1980). Theoretical bases of com-municative approaches to second language teaching and testing. Applied linguistics, 1(1), 1-47.

Cao, Y. (2014). A sociocognitive perspective on second language classroom willingness to communicate. TESOL Quarterly, 48(4), 789-814.

Cao, Y. (2011). Investigating situational willingness to communicate within second language classrooms from an ecological perspective. System, 39, 468-479.

Cao, Y., \& Philp, J. (2006). Interactional context and willingness to communicate: A comparison of behavior in whole class, group and dyadic interaction. System, 34, 480 493.

Dewaele, J-M. (2002). Psychological and sociodemographic correlates of communicative anxiety in L2 and L3 production. The International Journal of Bilingualism, 6, 23-39.

Dewaele, J-M., \& Furnham, A. (2000). Personality and speech production: A pilot study of second language learners. Personality and Individual Differences, 28, 355-365.

Donovan, L. A., \& MacIntyre, P. D. (2004). Age and sex differences in willingness to communicate communication apprehension, and self-perceived competence. Communication Research Reports, 21(4), 420-427.

Dörnyei, Z. (2005). The psychology of language learner: Individual differences in second language acquisition. Mahwah, NJ: Lawrence Erlbaum Associates.

Dörnyei, Z., \& Kormos, J. (2000). The role of individual and social variables in oral task performance. Language Teaching Research, 4(3), 275-300.

Fallah, N. (2014). Willingness to communicate in English, communication selfconfidence, motivation, shyness and teacher immediacy among Iranian English-major undergraduates: A structural equation modeling approach. Learning and Individual Differences, 30, 140-147.

Fraser, B. J., Fisher, D. L., \& McRobbie, C. J. (1996, April). Development, validation, and use of personal and class forms of a new classroom environment instrument. Paper 
presented at the Annual Meeting of the American Educational Research Association, New York.

Furnham A (1990). Language and personality. In H. Giles \& W. P. Robinson (Eds.), Handbook of language and social psychology (pp. 73-95). London: John Wiley \& Sons, Chichester.

Furnham, A., \& Monsen, J. (2009). Personality traits and intelligence predict academic school grades. Learning and Individual Differences, 19, 28-33.

Fushino, K. (2010). Causal relationships between communication confidence, beliefs about group work, and willingness to communicate in foreign language group work. TESOL quarterly, 44(4), 700-724.

Ghonsooly, B., Khajavy, G. H., \& Asadpour, S. F. (2012). Willingness to communicate in English among Iranian non-English major university students. Journal of Language and Social Psychology, 31(2), 197-211.

Horwitz, E. K., Horwitz, M. B., \& Cope, J. (1986). Foreign language classroom anxiety. Modern Language Journal, 70(2), 125-132.

Joe, H. K., Hiver, P., \& Al-Hoorie, A. H. (2017). Classroom social climate, selfdetermined motivation, willingness to communicate, and achievement: A study of structural relationships in instructed second language settings. Learning and Individual Differences, 53, 133e144.

John, O. P., \& Srivastava, S. (1999). The Big Five trait taxonomy: History, measurement, and theoretical perspectives. In L. A. Pervin, \& O. P. John (Eds.), Handbook of personality: Theory and research (pp. 102-138). New York: Guilford Press

Khajavy, G. H., Ghonsooly, B., Hosseini Fatemi, A., \& Choi, C. W. (2016). Willingness to communicate in English: A microsystem model in the Iranian EFL classroom context. TESOL Quarterly, 5O(1), 154-180.

Khany, R., \& Nejad, A. M. (2017). L2 willingness to communicate, openness to experience, extraversion, and 12 unwillingness to communicate: The Iranian EFL context. RELC Journal, 48(2), 241-255.

Lee, J. S. (2019). EFL students' views of willingness to communicate in the extramural digital context. Computer Assisted Language Learning, 32(7), 1-21.

Lin, Y. T. (2018). Taiwanese EFL learners' willingness to communicate in English in the classroom: Impacts of personality, affect, motivation, and communication confidence. The Asia-Pacific Education Researcher, 28(2), 101-113.

MacIntyre, P. D., Baker, S. C., Clément, R., \& Donovan, L. A. (2002). Sex and age effects on willingness to communicate, anxiety, perceived competence, and L2 motivation among junior high school French immersion students. Language learning, 52(3), 537-564. 
MacIntyre, P. D. (2007). Willingness to communicate in the second language: Understanding the decision to speak as a volitional process. The Modern Language Journal, 91(4), 564-576.

MacIntyre, P. D., \& Charos, C. (1996). Personality, attitudes, and affect as predictors of second language communication. Journal of Language and Social Psychology, 15, 3 26.

MacIntyre, P. D., Clément, R., Dörnyei, Z., \& Noels, K. A. (1998). Conceptualizing willingness to communicate in a L2: A situational model of L2 confidence and affiliation. Modern Language Journal, 82, 545-562.

MacIntyre, P. D. (1999). Language anxiety: A review of the research for language teachers. In D. Young (Ed.), Affect in foreign language and second language learning (pp. 24-46). Boston, MA: McGraw-Hill College.

MacIntyre, P. D., Burns, C., \& Jessome, A. (2011). Ambivalence about communicating in a second language: A qualitative study of French immersion students' willingness to communicate. The Modern Language Journal, 95(1), 81-96.

McCroskey, J. C., \& Baer, J. E. (1985, November). Willingness to communicate: The construct and its measurement: Paper presented at the annual convention of the Speech Communication Association, Denver, CO.

Ntalianis, F. (2010). Do personality and learning climate predict competence for learning? An investigation in a Greek academic setting. Learning and Individual Differences, 20, 664-668.

Oxford, R., \& Shearin, J. (1994). Language learning motivation: Expanding the theoretical framework. Modern Language Journal, 78, 12-28.

Oz, H. (2014). Big Five personality traits and willingness to communicate among foreign language learners in Turkey. Social Behavior and Personality: An International Journal, 42(9), 1473-1482.

Öz, H., Demirezen, M., \& Pourfeiz, J. (2015). Willingness to communicate of EFL learners in Turkish context. Learning and Individual Differences, 37, 269-275.

Pallant, J. (2013). SPSS survival manual. McGraw-Hill Education (UK).

Pawlak, M., \& Mystkowska-Wiertelak, A. (2015). Investigating the dynamic nature of L2 willingness to communicate. System, 50, 1-9.

Peng, J. (2012). Towards an ecological understanding of willingness to communicate in EFL classrooms in China. System, 40, 203-213.

Peng, J., \& Woodrow, L. (2010). Willingness to communicate in English: A model in the Chinese EFL classroom context. Language Learning, 60, 834-876. 
Peng, J. E., Zhang, L., \& Chen, Y. (2017). The mediation of multimodal affordances on willingness to communicate in the English as a foreign language classroom. TESOL Quarterly, 51(2), 302-331.

Piechurska-Kuciel, E. (2018). Openness to experience as a predictor of L2 WTC. System, 72, 190-200.

Rafiee, M., \& Abbasian-Naghneh, S. (2018). Prioritization of critical individual factors influencing willingness to communicate: AHP method. Journal of Multilingual and Multicultural Development, 1-14.

Syed, H., \& Kuzborska, I. (2018). Dynamics of factors underlying willingness to communicate in a second language. The Language Learning Journal, 53, 1-20.

Tabachnick, B. G., \& Fidell, L. S. (2001). Using multivariate statistics. New York: HarperCollins.

Tan, K. E., \& Phairot, E. (2018). Willingness to communicate among Thai EFL students: Does English proficiency matter? The Journal of Asia TEFL, 15(3), 590-602.

Warsi, J. (2004). Conditions under which English is taught in Pakistan: An applied linguistic perspective. Sarid Journal, 1(1), 1-9.

Weaver, C. (2005). Using the Rasch model to develop a measure of second language learners' willingness to communicate within a language classroom. Journal of Applied Measurement, 6(4), 396-415.

Wen, W. P., \& Clément, R. (2003). A Chinese conceptualisation of willingness to communicate in ESL. Language Culture and Curriculum, 16(1), 18-38.

Woodrow, L. J. (2006). Anxiety and speaking English as a second language. RELC Journal, 37(3), 308-328.

Yashima, T., MacIntyre, P. D., \& Ikeda, M. (2018). Situated willingness to communicate in an L2: Interplay of individual characteristics and context. Language Teaching Research, 22(1), 115-137.

Yashima, T., Zenuk-Nishide, L., \& Shimizu, K. (2004). The influence of attitudes and affect on willingness to communicate and second language communication. Language learning, 54(1), 119-152.

Yashima, T. (2002). Willingness to communicate in a second language: The Japanese EFL context. Modern Language Journal, 86, 54-66. 